\title{
Effect of substrate roughness on growth of diamond by hot filament CVD
}

\author{
AWADESH K MALLIK ${ }^{*, 1}$, S R BINU ${ }^{2}$, L N SATAPATHY ${ }^{4}$, CHANDRABHAS NARAYANA ${ }^{5}$, \\ MD MOTIN SEIKH ${ }^{3}$, S A SHIVASHANKAR ${ }^{1}$ and $S$ K BISWAS ${ }^{1,2}$ \\ Central Glass and Ceramic Research Institute, Kolkata 700 032, India \\ ${ }^{1}$ Materials Research Centre, ${ }^{2}$ Department of Mechanical Engineering, ${ }^{3}$ Solid State and Structural Chemistry Unit, \\ Indian Institute of Science, Bangalore 560 012, India \\ ${ }^{4}$ Ceramic Technological Institute, Bharat Heavy Electricals Limited, Bangalore 560 012, India \\ ${ }^{5}$ Jawaharlal Nehru Centre for Advanced Scientific Research, Bangalore 560 064, India
}

MS received 11 July 2008; revised 4 March 2010

\begin{abstract}
Polycrystalline diamond coatings are grown on Si (100) substrate by hot filament CVD technique. We investigate here the effect of substrate roughening on the substrate temperature and methane concentration required to maintain high quality, high growth rate and faceted morphology of the diamond coatings. It has been shown that as we increase the substrate roughness from $0.05 \mu \mathrm{m}$ to $0.91 \mu \mathrm{m}$ (centre line average or CLA) there is enhancement in deposited film quality (Raman peak intensity ratio of $s p^{3}$ to non-sp ${ }^{3}$ content increases from 1.65 to 7.13 ) and the substrate temperature can be brought down to $640^{\circ} \mathrm{C}$ without any additional substrate heating. The coatings grown at adverse conditions for $s p^{3}$ deposition has cauliflower morphology with nanocrystalline grains and coatings grown under favourable $s p^{3}$ condition gives clear faceted grains.
\end{abstract}

Keywords. Hot filament CVD; polycrystalline diamond coating; roughness; morphology; quality.

\section{Introduction}

Polycrystalline diamond has excellent mechanical, electrical and optical properties and is chemically inert (Kama et al 1983; Narayan et al 1992; Gruen 1999; Lee et al 1999; May 2000; Das and Singh 2007). To exploit these properties for engineering applications many techniques have been developed in the last three decades to deposit diamond films on engineering components. Hot filament assisted chemical vapour deposition technique (Kama et al 1983; Wang et al 2003; Sarangi et al 2008; Amorim et al 2009) is a relatively cheap low temperature process.

One of the main disadvantages of this process is the low growth rate, typically about $1 \mu \mathrm{m} / \mathrm{h}$ (Matsumoto 1982). The growth rate may be enhanced with increased methane $\left(\mathrm{CH}_{4}: \mathrm{H}_{2}\right)$ concentration but at the cost of film quality (Kama et al 1983; Narayan et al 1992); the morphology of the film degrades from a cubic facetted to a cauliflower or a spherical structure (Kobashi et al 1990). Takahashi et al (2002) have shown that increasing the methane concentration from $0.5 \%$ increases the adhesive toughness of the film as the crystal changes its phase from monocrystalline to polycrystalline with a reduction in grain size. The mechanical property, however, deteriorates

*Author for correspondence (amallik@cgcri.res.in) at high methane concentration of $5 \%$ as the grain size becomes very small (cauliflower morphology). The quality may, however, be improved by increasing the process temperature (Kondoh et al 1994), but this of course increases the cost.

Growth of diamond begins when individual carbon atoms nucleate onto the surface in such a way as to initiate the beginnings of an $s p^{3}$ tetrahedral lattice. When using natural diamond substrates (a process called homoepitaxial growth), the template for the required tetrahedral structure is already present, and the diamond lattice is just extended atom-by-atom as deposition proceeds. But for non-diamond substrates (heteroepitaxial growth), there is no such template for the $\mathrm{C}$ atoms to follow, and those $\mathrm{C}$ atoms that deposit in non-diamond forms are immediately etched back into the gas phase by reaction with atomic $\mathrm{H}$. As a result, the initial induction period before which diamond starts to grow can be prohibitively long (hours or even days). Growth of diamond films on a foreign substrate using a CVD process typically requires surface treatment in order to achieve a high nucleation density (Butler and Sumant 2008). To combat this problem, the substrate surface often undergoes a pre-treatment prior to deposition in order to reduce the induction time for nucleation and to increase the density of nucleation sites. This pre-treatment can involve a number of different processes. The simplest is abrasion of the substrate (Lee 
et al 1999) surface by mechanical polishing using diamond grit ranging in size from $10 \mathrm{~nm}-10 \mu \mathrm{m}$. The sample preparation techniques used for nucleation enhancement include scratching by diamond powder or any other abrasive (Mitsuda et al 1987; Chang et al 1988; Suzulu et al 1995), pre-deposition of interlayer (Feng et al 1993), seeding the substrate with diamond grit (Jansen et al 1990), electrical biasing of the substrates (Stoner et al 1992) and ion implantation of substrate surface (Hirabayashi et al 1988; Lin et al 1992). Among these, mechanical abrasion of substrate surface has proved most effective and cheapest. It has been employed for almost two decades of seeding the substrate with diamond particles through the use of a slurry of diamond particles dispersed in an appropriate solvent like alcohol, acetone etc and accompanied by ultrasonic agitation. With recent advent of detonated nanodiamond (DND) technology, it is very efficient to increase nucleation density and its uniformity using DND slurries for substrate scratching (Shenderova et al 2010). It is suggested that during agitation/scratching by abrasive material, residual powder or fragments are unavoidably left in the scratched groove and these act as seeds for diamond growth (Chang et al 1988; Suzulu et al 1995; Lee et al 1999). An alternative mechanism (Chang et al 1988; Suzulu et al 1995; Lee et al 1999) is that scratching with powder creates a change in the surface morphology, such as edges, steps, dislocations and other surface defects. These kinds of defects are labeled chemically active sites, which prefer to adsorb diamond precursors together due to enhanced bonding at high energy intersecting surfaces with a high density of unsaturated bonds and low coordination numbers. An order of $30 \mathrm{~nm}$ of substrate roughness created by mechanical abrasion has been found useful (Popovici et al 1992) for this purpose.

We have in this work investigated the effect of substrate roughness on the growth rate and coating quality with an aim to optimize process temperature and methane concentration. We deposited diamond in a hot filament reactor on $0.5 \mathrm{~mm}$ thick $\mathrm{Si}$ (single crystal) wafers. We have found that substrate roughening enables the lowering of process temperature and increase of methane concentration without impairing coating quality.

\section{Experimental}

A conventional hot filament chemical vapour deposition (HFCVD) reactor (figure 1) was used to deposit diamond on silicon substrates. The substrate heater consisted of a high purity alumina casing, holding a $0.5 \mathrm{~mm}$ thick (6 turns) tungsten filament. The casing was placed on a steel holder which held the substrate on top of the heater casing. The substrate used here was $n$-type Si (100) wafer of $0.5 \mathrm{~mm}$ thickness. The substrates were scratched using 1-3 $\mu \mathrm{m}$ diamond paste by ultrasonic method. The scratched substrates were rinsed in acetone, alcohol, dilute hydrofluoric acid solution and then washed in distilled water and dried before being placed on the alumina casing of the substrate heater.

The deposition chamber was evacuated to a pressure of $50 \times 10^{-3}$ mbar. The hydrogen was bled into the chamber at $200 \mathrm{sccm}$ (standard cubic centimeter per minute). The filament was heated to $2000^{\circ} \mathrm{C}$ monitored by a twowavelength optical pyrometer (MIKRON). The substrate temperature was controlled using a thermocouple and a feed back temperature-controller. Once the temperature was stabilized, methane was bled at a flow rate of $200 \mathrm{sccm}$ using a mass flow controller (Bronkhorst Hi-Tec, EL-Flow). The methane gas decomposed into radicals and the hydrogen gas split into atomic hydrogen to react at the substrate surfaces (Butler and Woodin 1993) and grew into tetrahedral diamond. The flow of methane, substrate temperature and the deposition time were varied in the study. Raman spectroscopy was done to monitor quality of the deposit. The Raman experiments were performed in a $90^{\circ}$ geometry using a Jobin Yvon Triax 550 tripple grating spectrometer equipped with cryogenic charge-coupled device camera, using diode-pumped frequency doubled solid state Nd-YAG laser of $532 \mathrm{~nm}$ (Model DPSS 532-400, Coherent Inc.). A super notch filter was used to eliminate the Rayleigh scattering. The deposited specimen was broken, polished and the cross section viewed in the scanning electron microscope to measure the film thickness. A profilometer (Taylor and Hobson, Talysurf) was used to measure the roughness of the surface, here we report the centre line average (CLA). The grain size of the deposited film was measured using an AFM (Explorer ${ }^{\mathrm{TM}}$, Veeco Instruments Inc.) in the contact mode.

\section{Results and discussion}

An unscratched silicon wafer has characteristic roughnesses of the orders of $0.025 \mu \mathrm{m}$ (CLA) and $0.69 \mu \mathrm{m}$

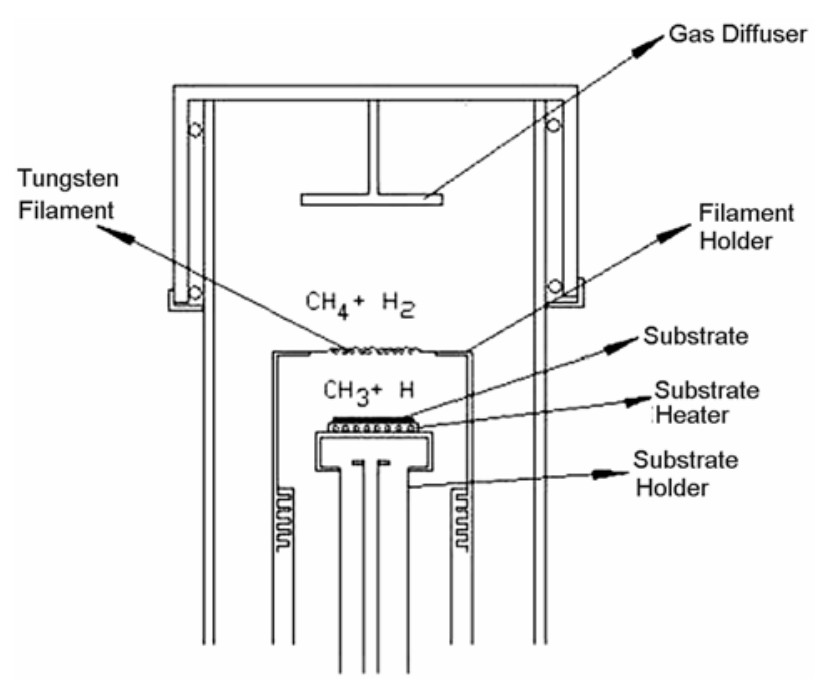

Figure 1. Schematic of HFCVD reactor. 
(CLA) on the two opposite faces. Scratching both faces yielded roughnesses of the orders of $0.045 \mu \mathrm{m}$ (CLA) and $0.988 \mu \mathrm{m}$ (CLA), respectively.

Our results show that the coating thickness $(\approx 6 \mu \mathrm{m})$ does not vary significantly with the substrate roughness but the morphology of the coating varies considerably. The coatings grown $(2 \%$ methane concentration,
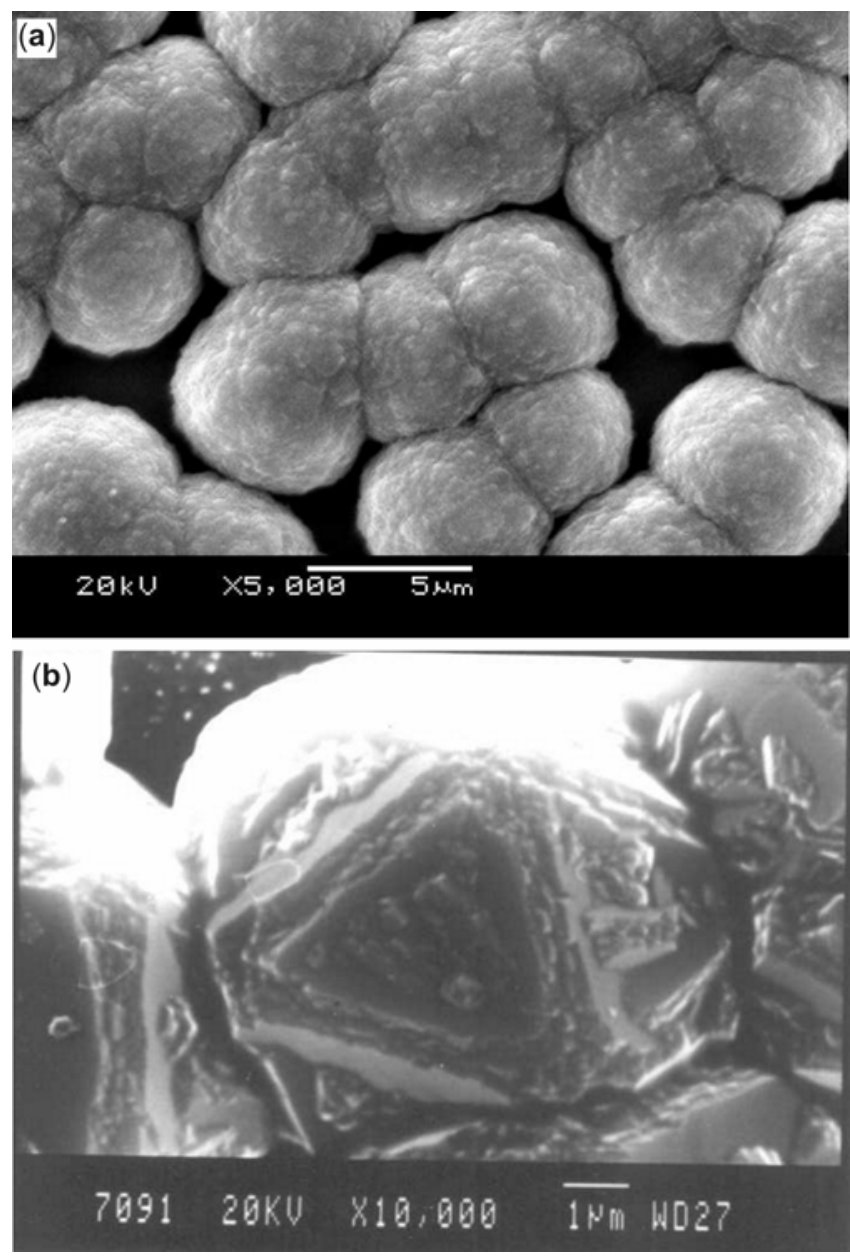

Figure 2. Morphology of diamond coatings grown on Si (100) substrates, $\mathrm{CH}_{4}$ concentration, $2 \%$; substrate temperature, $750^{\circ} \mathrm{C}$ : (a) smooth substrate, showing cauliflower morphology and (b) rough substrate, showing faceted morphology.

Table 1. Effect of substrate roughness on morphology of diamond coating

\begin{tabular}{|c|c|c|c|}
\hline Roughness & Morphology & $\begin{array}{c}\text { Methane } \\
\text { concentration } \\
(\%)\end{array}$ & $\begin{array}{c}\text { Substrate } \\
\text { temperature }\end{array}$ \\
\hline Smooth $(0 \cdot 045 \mu \mathrm{m})$ & Cauliflower & 2 & $750^{\circ} \mathrm{C}$ \\
\hline $\operatorname{Rough}(0.988 \mu \mathrm{m})$ & Faceted & 2 & $750^{\circ} \mathrm{C}$ \\
\hline Smooth $(0 \cdot 045 \mu \mathrm{m})$ & Faceted & 2 & $800^{\circ} \mathrm{C}$ \\
\hline $\operatorname{Rough}(0.988 \mu \mathrm{m})$ & Cauliflower & 2 & $700^{\circ} \mathrm{C}$ \\
\hline
\end{tabular}

$750^{\circ} \mathrm{C}$ substrate temperature) on the smooth (scratched) substrate $(\approx 0.045 \mu \mathrm{m}$, CLA $)$ has distinct cauliflower
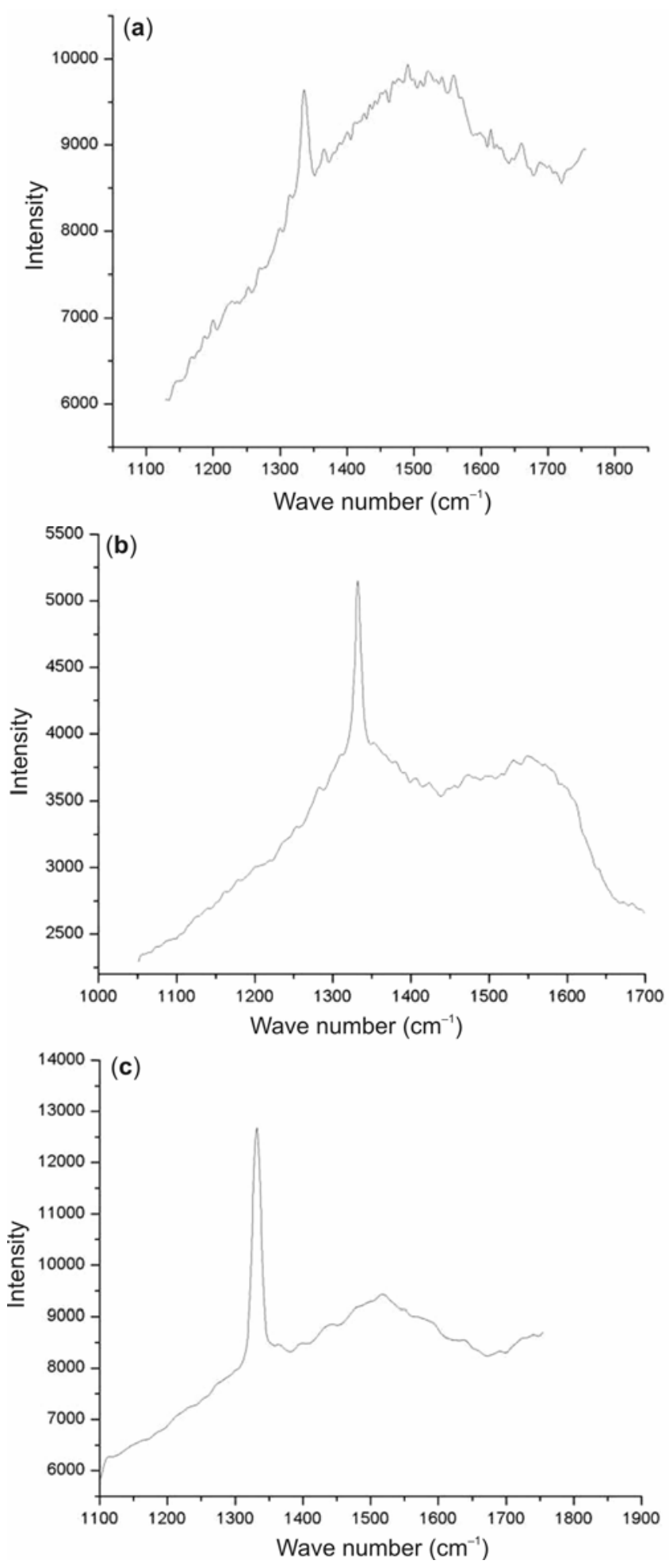

Figure 3. Raman spectra of diamond coating grown on $\mathrm{Si}(100)$ substrate: (a) substrate roughness, $0.05 \mu \mathrm{m}$ CLA; substrate temperature, $950^{\circ} \mathrm{C}$; methane concentration, $1.5 \%$, (b) substrate roughness, $0.85 \mu \mathrm{m} \mathrm{CLA}$; substrate temperature, $810^{\circ} \mathrm{C}$, methane concentration, $1.5 \%$ and (c) substrate roughness, $0.91 \mu \mathrm{m} \mathrm{CLA}$; substrate temperature, $900^{\circ} \mathrm{C}$; methane concentration, $3 \%$. 
Table 2. Effects of process parameters and substrate preparation on the quality of diamond coating.

\begin{tabular}{|c|c|c|c|c|c|c|c|c|c|c|c|c|}
\hline Row & $\begin{array}{l}\text { Figure } \\
\text { no. }\end{array}$ & $\begin{array}{c}\mathrm{CH}_{4}: \mathrm{H}_{2} \\
(\%)\end{array}$ & $\begin{array}{c}\text { Substrate } \\
\text { tempera- } \\
\text { ture } \\
\left({ }^{\circ} \mathrm{C}\right)\end{array}$ & $\begin{array}{c}\text { Substrate } \\
\text { heater }\end{array}$ & $\begin{array}{c}\text { Substrate } \\
\text { rough- } \\
\text { ness }\end{array}$ & $\begin{array}{c}\text { Coating } \\
\text { thick- } \\
\text { ness } \\
(\mu \mathrm{m})\end{array}$ & $\begin{array}{c}\text { Growth } \\
\text { rate } \\
(\mu \mathrm{m} / \mathrm{h})\end{array}$ & $\begin{array}{c}\text { Peak } \\
\text { position }\end{array}$ & FWHM & $\begin{array}{c}\text { Integrated } \\
\text { peak } \\
\text { intensity, } \\
1332 \mathrm{~cm}^{-1} \\
\left(I_{\mathrm{d}}\right)\end{array}$ & $\begin{array}{c}\text { Integrated } \\
\text { peak } \\
\text { intensity, } \\
1500- \\
1600 \mathrm{~cm}^{-1} \\
\left(I_{\mathrm{g}}\right)\end{array}$ & $\begin{array}{c}\text { Intensity } \\
\text { ratio } \\
\left(I_{\mathrm{d}} / I_{\mathrm{g}}\right)\end{array}$ \\
\hline 1 & Figure $3 a$ & a 1.5 & 950 & Yes & Smooth & 6.57 & 1.09 & 1333.9 & $12 \cdot 9$ & $1290 \cdot 78$ & 778 & 1.65 \\
\hline 2 & Figure $3 b$ & b $\quad 1.5$ & 810 & Yes & Rough & $5 \cdot 12$ & 0.84 & 1331.59 & $10 \cdot 526$ & 5435 & 944 & 5.75 \\
\hline 3 & Figure $3 c$ & 3 & 900 & Yes & Rough & 5.93 & 0.97 & $1332 \cdot 28$ & 8.488 & 1533 & 215 & $7 \cdot 13$ \\
\hline 4 & - & 2 & 640 & No & Smooth & 0 & 0 & - & - & - & - & - \\
\hline 5 & Figure 4 & 2 & 640 & No & Rough & $5 \cdot 92$ & 0.97 & $1331 \cdot 62$ & $13 \cdot 71$ & 3327 & 762 & $4 \cdot 36$ \\
\hline
\end{tabular}

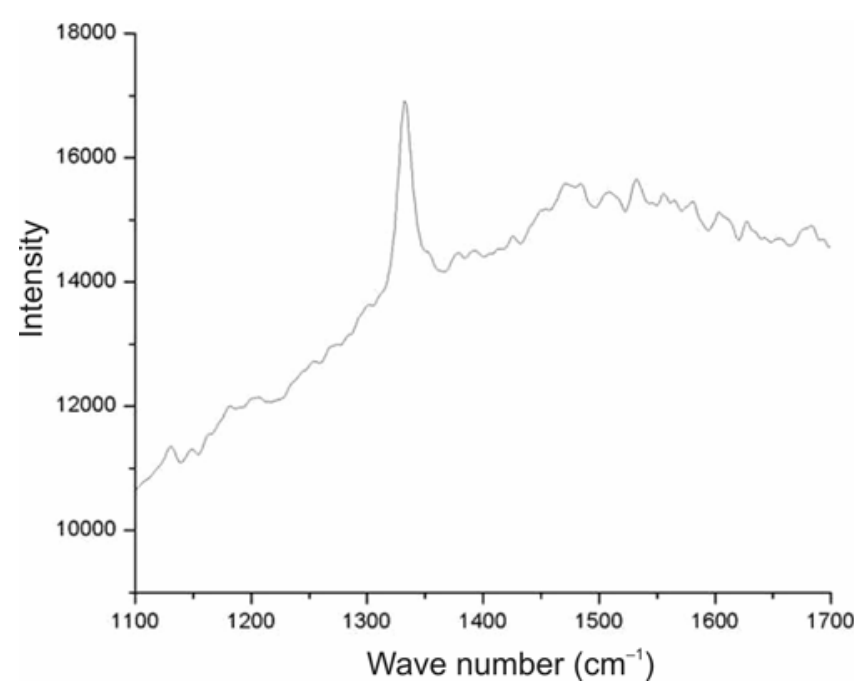

Figure 4. Raman spectra of diamond coating grown without the use of a substrate heater, substrate roughness, $0.94 \mu \mathrm{m}$ CLA; substrate temperature, $640^{\circ} \mathrm{C}$; methane concentration, $2 \%$.

morphology (figure 2a) with grain size in the 100-200 nm range. The coating grown $(2 \%$ methane concentration, $750^{\circ} \mathrm{C}$ substrate temperature) on the rough substrate ( $1 \mu \mathrm{m}$ CLA) showed clear faceted morphology (figure $2 \mathrm{~b}$, table 1) with grain size in the $3-5 \mu \mathrm{m}$ range. Increasing the temperature of the smooth substrate to $800^{\circ} \mathrm{C}$, however, yielded a faceted morphology of the diamond coating. We could obtain continuous films at low temperatures $\left(640-700^{\circ} \mathrm{C}\right)$ only when the methane concentration was more than $2 \%$ but the substrate face in such cases had always to be rough. The only disadvantage we could observe in attempting to manipulate surface morphology using roughness as a parameter was that not only did the faceted morphology showed higher $(0 \cdot 5-0.6 \mu \mathrm{m}, \mathrm{CLA})$ roughness than the cauliflower morphology (0.25$0.45 \mu \mathrm{m}$, CLA) but the same morphology obtained on a rough substrate showed a higher roughness than that obtained on a smoother substrate.

Figure 3a shows the Raman spectrum of a coating (thickness, $6.75 \mu \mathrm{m}$ ) deposited on a scratched smooth surface of a silicon wafer. The peak at $1332 \mathrm{~cm}^{-1}$ is characteristic of $\mathrm{C}$ tetrahedral whereas the hump at 1500 $1600 \mathrm{~cm}^{-1}$ is a characteristic of graphite. We mark the (diamond peak) coating quality by the ratio of the intensity of the peak to hump, the higher the $1332 \mathrm{~cm}^{-1}$ peak and lower the $1500-1600 \mathrm{~cm}^{-1}$ hump intensity we infer an enhancement of coating quality. Table 2 summarizes the key experimental results. It is well established (Kondoh et al 1994) that decreasing the substrate temperature deteriorates the coating quality. By comparing rows 1 and 2 (table 2), we, however, observe that the methane concentration remaining the same, it is possible to suppress this effect (due to reduction of substrate temperature by $140^{\circ} \mathrm{C}$ ) completely and improve the coating quality 3.5 times (compare intensity ratio and also see figure $3 \mathrm{~b}$ ) by making the 'lower temperature' substrate rough. The cost of doing this is a lowering of coating growth rate (by $20 \%$ ) and an enhancement of coating roughness from $0 \cdot 1 \mu \mathrm{m}$ (CLA) to $0 \cdot 22 \mu \mathrm{m}$ (CLA).

A similar result is obtained by increasing the methane concentration. It is known (Kobashi et al 1990) that increasing methane concentration deteriorates the coating quality but increases the growth rate. By comparing rows 1 and 3 in table 2 and figures $3 a$ and $3 c$, it is clearly seen that this tendency for deterioration of coating quality is completely superceded by the 'roughness' effect and coating quality improves several times. This unfortunately happens at the cost of neutralizing the expected increase in growth rate due to an increase in methane concentration.

We next decrease the substrate temperature by removing the substrate heater. We found the growth to be discontinuous when the deposition was done on the smooth substrate (row 4, table 2). Roughening the substrate, however, produced a high quality coating (row 5 , table 2 , figure 4) even at a substrate temperature as low as $640^{\circ} \mathrm{C}$.

The substrate roughness effect on diamond growth can be explained as follows: it is a well known fact that nucleation of diamond requires seeding the substrate with diamond (Chang et al 1988; Jansen et al 1990; Suzulu et al 1995; Lee et al 1999). As we have scratched the 
substrate with 1-3 micron diamond paste before deposition in ultrasonic bath, the bare substrates got roughened and the diamond particles in the paste got stuck in the valleys of the roughened surface. As the depth of valley increases with surface roughness, more diamond particles get embedded within the asperities and troughs of the surface. This enhances nucleation of the diamond crystal and its growth behaviour.

\section{Conclusions}

The substrate roughness is shown here to have a strong effect on the morphology and quality of diamond coatings grown on Si (100) substrate by hot filament CVD technique. Increasing the substrate roughness encourages faceted morphology and improves coating quality. We conclude that roughening of the substrate allows the lowering of substrate temperature and enhancement of methane concentration, both practices favoured for the reduction of cost of production of polycrystalline diamond coating, without compromising on the quality and nature of the coating.

\section{Acknowledgements}

The authors thank the Indian Space Research Organization for financial support and the CTI, BHEL, for making available deposition facilities.

\section{References}

Amorim A, Nascente P A P, Trava-Airoldi V J, Corat E J, Alves A R and Moro J R 2009 Vacuum 831054

Butler J E and Woodin R L 1993 Philos. Trans. R. Soc. London A342 209
Butler J E and Sumant A V 2008 Chem. Vap. Depos. 14145

Chang C P, Flamn D L, Ibbotson D E and Mucha J A 1988 J. Appl. Phys. 631744

Das D and Singh R N 2007 Int. Mater. Rev. 5229

Gruen Dieter M 1999 Ann. Rev. Mater. Sci. 29211

Feng Z, Komvipoulos K, Brown I G and Bogy D B 1993 J. Appl. Phys. 742841

Hirabayashi K et al 1988 Appl. Phys. Lett. 531815

Jansen F, Machonkin M A and Kuhman D E 1990 J. Vac. Sci. Technol. A8 3785

Kama M, Sato Y, Matsumoto S and Setaha N 1983 J. Cryst. Growth 62642

Kobashi K, Nishimura K, Miyata K, Kumagai K and Nakaue A 1990 J. Mater. Res. 52469

Kondoh K, Ohta T, Mitomo T and Ohtsuka K 1994 Diam. Rel. Mater. 3270

Lee S T, Lin Z and Jiang X 1999 Mater. Sci. \& Eng. R25 123

Lin S J et al 1992 Appl. Phys. Lett. 601559

Matsumoto S 1982 J. Mater. Sci. 173106

Mitsuda K, Kojima Y, Yoshida T and Akashi K 1987 J. Mater. Sci. 221557

Narayan J, Godbole V P, Matera G and Singh R K 1992 J. Appl. Phys. 71966

May Paul W 2000 Philos. Trans. R. Soc. London A358 473

Popovici Galina and Prelas M A 1992 Phys. Status Solidi 132 233

Sarangi S K, Chattopadhyay A and Chattopadhyay A K 2008 Appl. Surf. Sci. 2543721

Shenderova O, Hens S and McGuire G 2010 Dia. Rel. Mater. 19260

Stoner B R, Ma G H M, Wolter S D and Glass J T 1992 Phys. Rev. B45 11067

Suzulu K, Swabe A, Yasuda H and Inuzuka T 1995 Appl. Phys. Lett. 661900

Takahashi H, Kamiya S and Saka M 2002 J. Am. Ceram. Soc. 85179

Wang A, Sun C, Huang R, Wen L, Cailiao Kexue and Yu Jishu 2003 J. Mater. Sci. \& Technol., China, USA 1922 